\title{
The returns to farm afforestation in Ireland: a discounted cash flow analysis
}

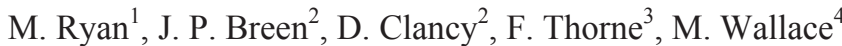

${ }^{1}$ Forestry Development Unit, Teagasc, Athenry, Co. Galway, Ireland, ${ }^{2}$ Rural Economy Research Centre, Teagasc, Athenry, Co. Galway, Ireland, ${ }^{3}$ Rural Economy Research Centre, Teagasc, Kinsealy, Dublin 17, Ireland, ${ }^{4}$ School of Agriculture, Food Science and Veterinary Medicine, University College Dublin, Belfield, Dublin 4, Ireland

Email: james.breen@teagasc.ie

Introduction Irish afforestation rates have been in decline over the past 10 years and currently are more than 60 percent below government targets, despite increases in the value of the forest establishment grants and premium. This decline in afforestation rates has also occurred despite the decoupling of direct payments in Irish agriculture in 2005 and the opportunity for Irish farmers to stack their Single Farm Payment (SFP) entitlements and afforest up to 50 percent of their farm. The aim of this analysis is to calculate the returns to forestry under alternative opportunity costs from the conventional agricultural activities being superseded.

Material and methods The Discounted Cash Flow (DCF) approach allows for the comparison of investments with different cash flow profiles such as annual versus multi-period systems and is used to evaluate the afforestation investment decision. The Net Present Value (NPV) values an investment as the sum of the project's net cash flows discounted at the businesses' opportunity cost of capital (Boardman et al. 2001). This paper compares the NPV of three alternative afforestation options. The opportunity cost of land, is accounted for through the inclusion of foregone returns from five superseded activities; grazing land rental, lowland sheep, store to finish beef, spring barley and winter wheat. The cost and revenue assumptions for the five superseded enterprises are in Table 1.

Table 1 Gross margin and working capital released per hectare for the superseded enterprises

\begin{tabular}{llllll}
\hline \hline & Land Rental & Spring Barley & Winter Wheat & Lowland Sheep & \multicolumn{2}{c}{ Store to Finished } \\
& & & & & Beef \\
\cline { 2 - 6 } Gross Margin & $€ 236$ & $€ 260$ & $€ 435$ & $€ 365$ & $€ 210$ \\
Working capital released & - & $€ 291$ & $€ 487$ & $€ 50$ & $€ 928$ \\
\hline \hline
\end{tabular}

The returns to forestry are calculated using the Forestry Investment Valuation Estimator (FIVE), a Teagasc research and advisory support tool. In this analysis the FIVE is used to calculate the costs and returns to three typical Irish forest scenarios Sitka spruce (SS), Ash and Mixed (ash, SS and Japanese Larch (J1)). Details of the scenarios are outlined in Table 2. All three afforestation scenarios assume a plantation of 10 hectares, a rotation length of 40 years, productive area of $85 \%$, 'normal' forest thinning and a discount rate of 5\%. All agricultural prices and costs were inflated to 2009 levels, while forestry prices and costs are based on a ten year average. The resulting normalised margins for forestry and the superseded enterprises are held constant over the economic life of the project. .

Table 2 Assumptions for alternative forest scenarios

\begin{tabular}{llll} 
& SS & Ash & Mixed \\
\cline { 2 - 4 } Tree Mix & SS 80\%/J1 20\% & Ash 100\% & SS 48\% / J1 12\%/Ash 40\% \\
Yield Class (Productivity) & SS $-22 / \mathrm{Jl}-12$ & Ash -10 & SS - 22/ J1 - 12/ Ash - 10 \\
Grant Premium Category (GPC) & GPC 3 & GPC 5 & GPC 3 (60\%)/GPC 5 (40\%) \\
\hline
\end{tabular}

Results The results indicate that the NPV in all cases are positive, except for Ash with a superseded enterprise of winter wheat. Despite receiving a higher annual premium, the Ash scenario has a lower NPV than SS regardless of the superseded enterprise. This is likely as a result of the significantly lower volume of timber produced. However over the last few years Ireland has seen an increase in the planting of broadleaves, which may have reflected the higher annual premium payable on broadleaves, as well as changes in the preferences of farm-foresters and increased afforestation on better quality soils. Table 3 below presents the NPV for each of the three afforestation scenarios with the five alternative superseded enterprises.

Table 3 Investment performance in per hectare terms with alternative assumptions about the superseded activity

\begin{tabular}{llllll}
\hline \hline & Land Rental & Spring Barley & Winter Wheat & Lowland Sheep & Store to Finished Beef \\
& NPV $(€)$ & NPV $(€)$ & NPV $(€)$ & NPV $(€)$ & 5,343 \\
\hline SS & 4,035 & 3,908 & 1,194 & 1,933 & 3,832 \\
Ash & 2,524 & 2,397 & -317 & 422 & 4,740 \\
Mixed & 3,432 & 3,304 & 591 & 1,330 & \\
\hline \hline
\end{tabular}

Conclusions Despite the decline in afforestation rates over the past 10 years, this analysis indicates that the returns to forestry compare favourably with the superseded enterprises examined. The existence of a re-planting requirement after clear-felling means that forestry is in effect a permanent decision and it is unclear as to whether or not farmers will perceive the higher returns from forestry as being sufficient to offset the permanent nature of the afforestation decision.

Acknowledgements The authors acknowledge funding from COFORD.

\section{References}

Boardman, A.E., Greenberg, D.H., Vining, A.R., and Weimer, D.L. 2001. Cost-Benefit Analysis: Concepts and Practice. $2^{\text {nd }}$ Edition, Prentice Hall, New Jersey, USA 